\title{
Effects of Annealing on the Structural and Optical Properties of Silver Thin Films
}

\author{
*OSANYINLUSI, O; ALABI AB; YUSUF, KA; OROSUN, MM
}

\author{
Department of Physics, University of Ilorin, Ilorin, Kwara State. \\ *Corresponding Author Email: adetolusi@gmail.com ; Phone No: 08060252268
}

\begin{abstract}
Silver thin films were prepared on glass substrates using chemical bath method. The thin films were annealed at different temperatures of 100 and $200^{\circ} \mathrm{C}$ for 1 hour. The samples, as-prepared and annealed were characterized using X-ray diffractometer (XRD) and Uv-Vis spectrophotometer. XRD results revealed that silver films present a cubic phase with (111) preferred orientation. The XRD result and analysis also revealed that the intensity of the peaks and the crystallite size increase with increase in annealing temperature. All the films showed very low transmittance within the visible region with the $200^{\circ} \mathrm{C}$ annealed film having the highest at $1.4 \%$. Reflectance was found to reduce from $65 \%$ for the as-deposited film to as low as $17 \%$ for the $200^{\circ} \mathrm{C}$ annealed film within the visible region of the wavelength. The reflectance reduces with increase in annealing temperature. The films also showed low percentage absorbance within the UV region of the wavelength with the $200^{\circ} \mathrm{C}$ annealed film having the highest absorbance of $2.79 \%$.
\end{abstract}

\section{DOI: https://dx.doi.org/10.4314/jasem.v23i12.1}

Copyright: Copyright (C) 2019 Osanyinlusi et al. This is an open access article distributed under the Creative Commons Attribution License (CCL), which permits unrestricted use, distribution, and reproduction in any medium, provided the original work is properly cited.

Dates: Received: 04 October 2019; Revised: 11 November 2019; 23 November 2019

Keywords: Annealing, Thin films, XRD, Optical properties, Spectrophotometer, Silver

Interest in metal films as contacts in microelectronic devices such as aluminium and silver, has increased for a wide range of applications including heatreflecting mirrors (Volkonen and Karlsson, 1987), the field of flat panel displays (Meiss et al, 2009), antireflection coatings (Bouhafs et al, 1998), organic light-emitting diodes (Hofmann et al, 2011), gas sensors (Xu et al, 2000) and as contact electrodes in solar cells (Yang et al, 2011). The ability to deposit thin films of various materials is important for the fabrication of modern microelectronic devices and for enabling a variety of investigations of fundamental physical principles (Zakia et al., 2014). The advantages of the $\mathrm{Ag}$ thin film application on microelectronic devices are as follows: (1) Low specific resistivity, (2) Good thermal stability, (3) High uniformity across the flat substrate, (4) Low particle contamination, (5) Good adherence to substrate, (6) Low manufacturing costs (Chia-Ching and Chia-Hsuansua, 2016).

Silver thin films have been studied widely because of their extensive applications in different industries and medical science. Also they are good candidate as interconnectors in electronic devices and electrical contacts in high temperature superconductor (HTSC) thin film devices (Winau et al., 1992). They can achieve unique optical and electrical properties and can have better performance relative to other metal films in optical applications. Silver layers are ideal reflecting and conducting electrodes for thin film solar cells (Hajakbari and Ensandoust, 2016). Ag thin films had been prepared by several techniques including thermal evaporation (Mohammed et. al. 2018), DC magnetron sputtering (Hajakbari and Ensandoust, 2015). In the present investigation, Chemical bath deposition was employed to prepare Ag films and the effect of annealing on the structural and optical properties of Ag films at different temperatures were investigated.

\section{MATERIALS AND METHODS}

Substrate Cleaning: Commercially available glass slides of dimension $75 \mathrm{~mm}$ x $25 \mathrm{~mm}$ x $2 \mathrm{~mm}$ were used as substrates for the deposition of $\mathrm{Ag}$ thin films. Using ultrasonic cleaning, the glass slides were successively rinsed in chromic acid, acetone and distilled water.

Silver thin films preparation: For the deposition of $\mathrm{Ag}$ thin films, Silver nitrate $\left(\mathrm{AgNO}_{3}\right)$, and triethanolamine (TEA) purchased from Merck were used without further purification. Silver nitrate $\left(\mathrm{AgNO}_{3}\right)$ and triethanolamine (TEA) were used as source material for $\mathrm{Ag}^{+}$ion and complexing agent respectively.

$0.25 \mathrm{~g}$ of silver nitrate $\left(\mathrm{AgNO}_{3}\right)$ solid was dissolved in $5 \mathrm{ml}$ of distilled water in a $100 \mathrm{ml}$ beaker. There after triethanolamine (TEA) solution was added drop wise 
with constant stirring using magnetic stirrer until the initially formed precipitate was dissolved. Distilled water was added to make a total volume of $80 \mathrm{ml}$. The $\mathrm{pH}$ value of the bath was maintained as 8.0. The well cleaned glass substrates were slowly immersed vertically into the bath and the bath was brought to and kept at $50^{\circ} \mathrm{C}$ under continuous stirring.

After a period of 50 mins, the coated slides were removed from the bath, thoroughly rinsed with distilled water, and air dried. Two samples were annealed at different temperatures of $100^{\circ} \mathrm{C}$ and $200^{\circ} \mathrm{C}$ while one sample was kept as-prepared.

Structural analysis of the samples was determined using X-ray diffraction (XRD) (model ANCHOR analytical Expert PRO X-ray diffraction) using $\mathrm{Cu} \mathrm{K}$ $\alpha$ radiation $(\lambda=1.5406 \AA)$ operated at voltage of $45 \mathrm{kV}$ and current of $40 \mathrm{~mA}$. The optical properties of the films were examined using UV-Visible spectrophotometer in the wavelength range of $300 \mathrm{~nm}$ $900 \mathrm{~nm}$

\section{RESULTS AND DISCUSSION}

Structural Properties: Figures 1-3 show the XRD pattern for the as-prepared and annealed Ag thin films deposited at 50 mins. It is inferred from the figures that all the spectra exhibit peak at $2 \theta$ equal to $37.89^{\circ}$ corresponding to the orientation along (111) direction. In addition, weak diffraction peaks also appear at $2 \theta$ equal to $44.08^{\circ}$ and $64.25^{\circ}$ which correspond to orientation along (200) and (220) plane respectively, thus confirming the presence of cubic Ag phase. The results are in good agreement with the results observed by Hajakbari and Ensandoust (2015). The high intensity and sharp peaks in XRD patterns confirm the highly oriented and polycrystalline nature of the $\mathrm{Ag}$ films prepared in this study. It is also observed that the intensity of the peaks increases with increase of the annealing temperature.

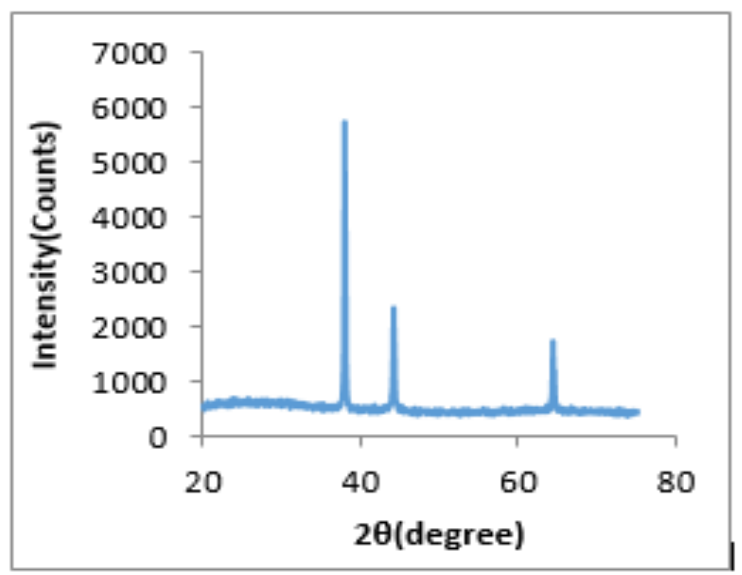

Fig. 1: XRD pattern of as deposited Ag thin film
The average crystallite size is estimated using DebyeSherrer's formula (Cullity, 1978)

$D=\frac{K \lambda}{\beta \operatorname{Cos} \theta}$

Where $\mathrm{D}$ is the crystallite size, $\lambda$ is the wavelength of $\mathrm{CuK} \alpha$ radiation $(\lambda=1.5406 \AA), \mathrm{k}=0.9$ is the shape factor, $\theta$ is the Bragg angle and $\beta$ is the experimental full-width at half maximum on the respective diffraction peak. It was observed that an increase in the annealing temperature of the films introduces variations in the crystallite sizes and FWHM. These variations are shown in Table 1 for the (111) plane of the films. The table shows that increasing the annealing temperature results in Ag films with higher crystallite size and lower width of the diffraction peak (FWHM). The maximum Crystallite size is $36.97 \mathrm{~nm}$ when the annealing temperature is $200^{\circ} \mathrm{C}$. Decrease in the width of the diffraction peaks suggests that annealing at higher temperature produces better quality crystal (Ezema Nwankwo, 2010). There is no significant change in the peaks position with annealing.

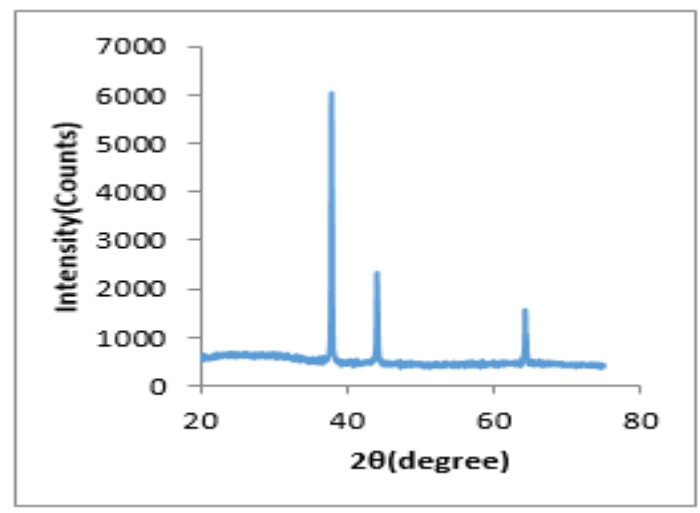

Fig. 2: XRD pattern of annealed $\mathrm{Ag}$ thin film at $100^{\circ} \mathrm{C}$

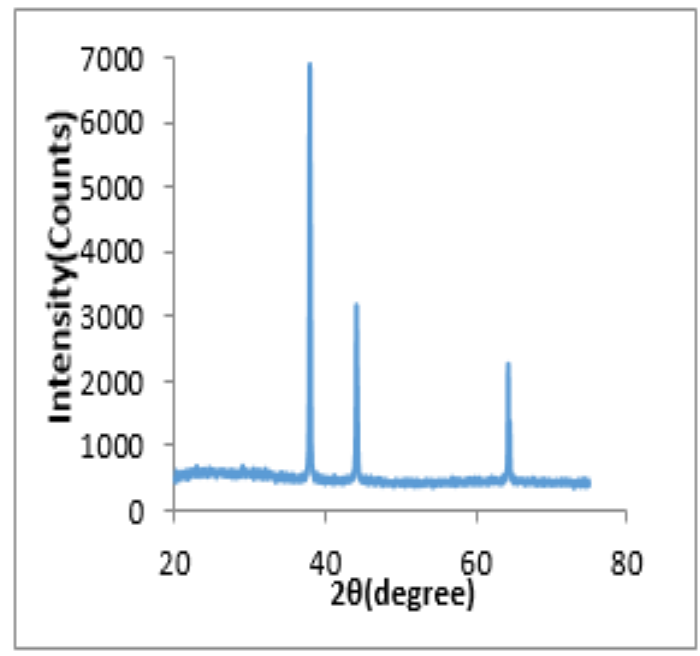

Fig. 3: $\mathrm{XRD}$ pattern of annealed $\mathrm{Ag}$ thin film at $200^{\circ} \mathrm{C}$

OSANYINLUSI, O; ALABI AB; YUSUF, KA; OROSUN, MM 
Table 1: Variation of the (111) Plane Crystallite Size and Full Width at Half Maximum (FWHM) of Ag thin films with Annealing Temperature.

\begin{tabular}{cccccc}
\hline $\begin{array}{c}\text { Annealing Temp } \\
\left(0^{\circ} \mathrm{C}\right)\end{array}$ & $\begin{array}{c}\mid 2 \theta \\
\text { (degree) }\end{array}$ & $\begin{array}{c}\text { Crystallite size } \\
(\mathrm{nm})\end{array}$ & $\begin{array}{c}\text { FMHW } \\
\text { (degree) }\end{array}$ & $\begin{array}{r}\text { Intensity } \\
\text { (counts) }\end{array}$ & $\begin{array}{r}\text { D-spai } \\
(\mathrm{nm}\end{array}$ \\
\hline As-prepared & 37.89 & 26.38 & 0.1791 & 5234.22 & 2.3 \\
100 & 37.90 & 36.93 & 0.1279 & 5411.23 & 2.3 \\
200 & 37.91 & 36.97 & 0.1278 & 6262.69 & 2.3 \\
\hline
\end{tabular}

Optical Properties: Fig 4 shows the transmittance spectra for the as- prepared and annealed $\mathrm{Ag}$ thin films. From the figure, it can be observed that all the films, as-deposited and annealed exhibit a metallic behavior with almost zero transmittance, with the film annealed at $200^{\circ} \mathrm{C}$ having the highest transmittance of about $1.4 \%$ within the UV region. Also, the transmittance spectra show a resonant increase in transmittance at wavelength of about $320 \mathrm{~nm}$ for all films, which can be due to the localized surface Plasmons (Al-Kuhaili, 2007). Similar result was reported by Hajakbari and Ensandoust (2016).

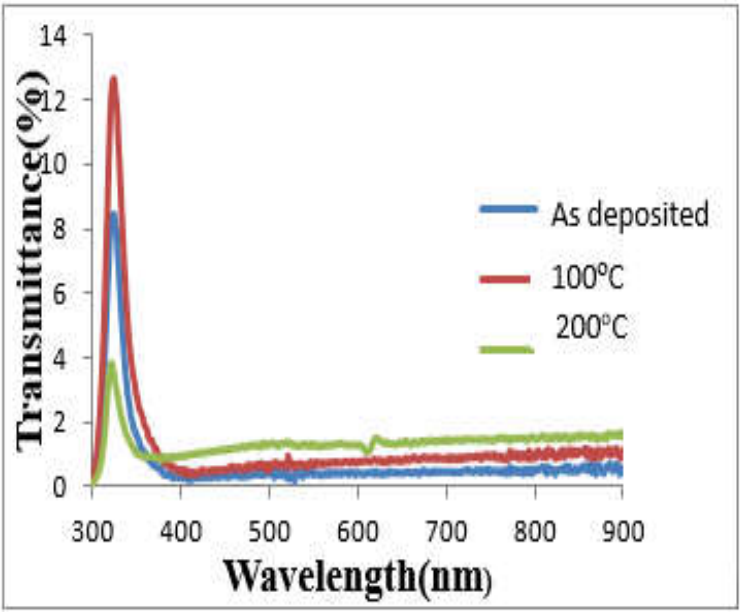

Fig. 4: Plot of $\% \mathrm{~T}$ against $\lambda(\mathrm{nm})$ for as-deposited and annealed Ag thin films

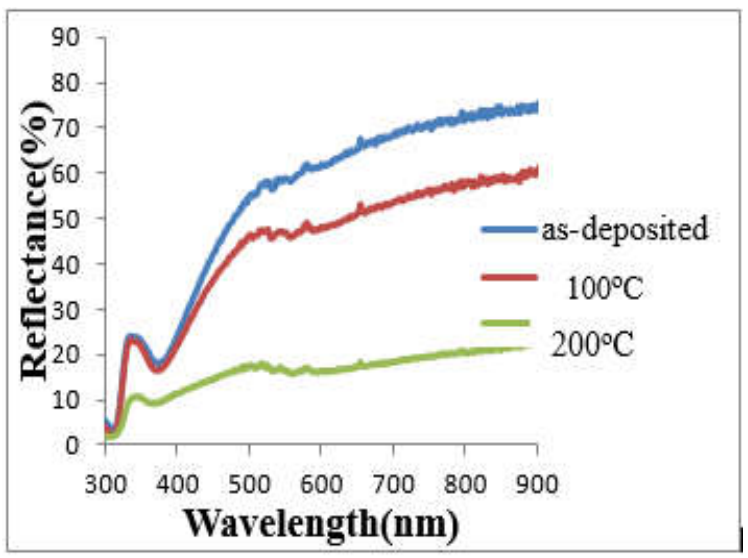

Fig 5: Plot of $\% \mathrm{R}$ against $\lambda$ for as-deposited and annealed $\mathrm{Ag}$ thin films
Figure 5 shows the reflectance spectral for asdeposited and annealed Ag thin films. From the figure, it can be observed that all the films exhibit an increase in reflectance as the wavelength increases. It is also observed that the reflectance reduces as the annealing temperature increases. This is in agreement with the finding of Chia-Ching and Chia-Hsuansua (2016). The as-deposited film have a maximum reflectance of $65 \%$ within the UV region and $73 \%$ at the near infrared region, as compared to $200^{\circ} \mathrm{C}$ annealed film with $17 \%$ and $20 \%$ respectively.

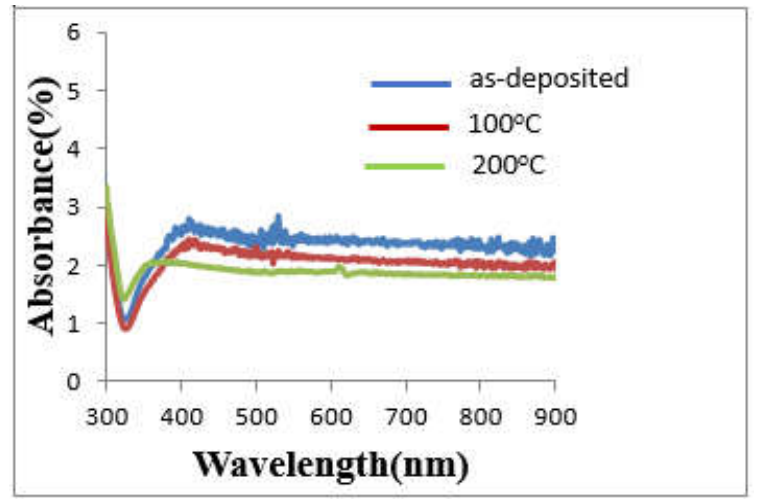

Fig 6: Plot of $\%$ A against $\lambda$ for as-deposited and annealed Ag thin films

The absorbance spectra of the Ag films annealed at different temperatures, in the wavelengths range of $300-900 \mathrm{~nm}$ is shown in Fig. 6. The figure reveal that all the films exhibit low absorption, with the $200^{\circ} \mathrm{C}$ annealed film having the highest absorbance between $2.79-2.36$ and $100^{\circ} \mathrm{C}$ annealed film having absorbance between $2.26-1.85$ within the UV region of the spectrum.

Conclusion: The role of annealing temperature on silver thin films prepared by chemical bath deposition method has been investigated. XRD study shows that the thin films are polycrystalline in nature. It was deduced that as the annealing temperature increase, the peak of the preferred orientation and the crystallite size increases. Optical study shows that annealing increases the transmission and reduces the reflectance of the films within the visible region of the wavelength. The results showed that the material can be applied in optoelectronic devices, where it can serve as a reflection coatings.

\section{REFERENCES}

Al-Kuhaili, MF (2007), Characterization of thin films produced by the thermal evaporation of silver oxide. J. Phys. D. Appl. Phys. 40: 2847 
Bouhafs, D; Moussi, A; Chikouche, A; Ruiz JM (1998). Design and simulation of antireflection coating systems for optoelectronic devices. Application to silicon solar cells. Sol. Ener. Mat. Sol. Cel. 52: 79-93

Chia-Ching, W; Chia-Hsuansua H. (2016), Effect of annealing temperature on the properties of silver films, Inter. J. Elect, Elect. D. Comm.4: 36

Cullity, B. (1978), Elements of X-ray diffraction. 2nd ed. Addison-Wesley; 102

Ezema, FI; Nwankwo, UOA (2010). Effect of annealing temperature on the structural and optical properties of zinc oxide $(\mathrm{ZnO})$ nanocrystals prepared by sol gel. Dig. J. Nano. Bio.5: 981 - 988

Hajakbari F; Ensandoust, M (2016), Study of Thermal Annealing Effect on the Properties of Silver Thin Films Prepared by DC Magnetron Sputtering, 5th International Science Congress \& Exhibition APMAS2015, Lykia, Oludeniz.129; 680 - 681

Hofmann, S; Thomschke, M; Lussen, B; Leo, K (2011), Top-emitting organic light-emitting diodes. Opt. Exp.19; 1250-1264
Meiss, J; Riede, MK; Leo, K. (2009), Optimizing the morphology of metal multilayer films for indium tin oxide (ITO)-free inverted organic solar cells. J. Appl. Phys. 105; 1-5

Volkonen, E; Karlsson B. (1987), Optimization of metal -based multilayers for transparent heat mirrors. Int. J. En. Res.11; 397-403

Winau, D; Koch, R; Weber, M; Rieder, KH.(1992),Intrinsic stress of Ag and Au electrical contact films for high temperature superconductor thin films. Appl. Phys. Lett. 61, 279

Xu, J; Shun, Y; Pan, Q; Qin, J (2000), Sensing characteristics of double layer film of $\mathrm{ZnO}$. Sen. and Act. 66; 161-163.

Yang, L; Zhang, T; Zhou, H; Price, SC; Wiley, BJ; You W (2011), Solution- processed flexible polymer solar cells with silver nanowire electrodes. Am. Chem. Soc. Appl. Mat. Int.3; 4075-4084

Zakia, F; Nazir, M; Ali, H. (2014). Optical, morphological and electrical properties of silver and aluminium metallization contacts for solar cells. Amer. J. Mod Phys. 3; 45-50 